\title{
Statistics anxiety in university students in assessment situations
}

Frias-Navarro, Dolores ${ }^{\text {; }}$ Monterde-i-Bort, Hector ${ }^{\text {; }}$ N Navarro-Gonzalez, Nuria ${ }^{\text {; }}$; Molina-Palomero Olaya ${ }^{a}$; Pascual-Soler, Marcos ${ }^{\mathrm{b}}$; Perezgonzalez, Jose ${ }^{\mathrm{c}}$ and Longobardi, Claudio. ${ }^{\text {d }}$

${ }^{a}$ Department of Methodology of the Behavioural Sciences, University of Valencia, Spain, ${ }^{b}$ ${ }^{b}$ Department of Methodology, ESIC Business \& Marketing School, Spain, ${ }^{c}$ Business School, Massey University, New Zealand, ${ }^{\mathrm{d}}$ Department of Psychology, University of Turin, Italy

\begin{abstract}
Many students have feelings of state anxiety when taking exams, and these feelings probably affect their performance. Statistics courses have been identified as producing the most anxiety. The purpose of our study is to measure statistics anxiety throughout an academic course (pre-test and three assessments) in order to observe its change and analyze the relationship between statistics anxiety and academic achievement. The sample is composed of 30 Psychology students taking a course in research designs and statistics $(26.7 \%$ men and $73.3 \%$ women) with a mean age of 20.31 years $(S D=3.76)$. The results show that the students begin with a high level of statistics anxiety that gradually declines as the course progresses and they study the course materials. Moreover, the final achievement in the subject maintains an inverse relationship with the level of statistics anxiety. The recommendation is to present the detailed contents of the teaching guide on the first day of the course in order to reduce students' anxiety and uncertainty when beginning a statistics course. Financial support: Project UV-INV-AE17-698616. University of Valencia. Spain.
\end{abstract}

Keywords: statistics anxiety; academic achievement; trait anxiety. 


\section{Introduction}

Statistics anxiety is a specific area of research due to students' difficulties in learning statistics and mathematics contents in any educational cycle (Badenes-Ribera, FriasNavarro, Monterde-i-Bort, \& Pascual-Soler, 2015; Chernoff, \& Sriraman, 2014; Monterdei-Bort, Frias-Navarro, \& Pascual-Llobell, 2010; Onwuegbuzie \& Wilson, 2003). These difficulties do not necessarily arise from poor academic training or low abilities. Instead, some of the other intervening factors are students' erroneous perceptions about statistics, about their lack of mathematic abilities, or about the horror stories they have heard for years about the difficulty of the subject, all of which can produce anxiety. The results of the studies by Onwuegbuzie and Wilson (2003) and Onwuegbuzie (2004) indicate that $80 \%$ of students express anxiety about statistics, and this may be the reason many of them delay taking the subject and decide not to take the exam until the end of their academic training.

An exam situation is a challenging, complex process for the individual, who must approach it as a situation of stress requiring the use of cognitive and behavioral strategies to administer the external and/or internal demands of this type of situation, based on his/her own resources (Folkman \& Lazarus, 1985). Each individual has a coping style that s/he employs in situations of stress. In addition, in a given stressful situation, such as an exam, the individual must use specific coping responses linked to certain thoughts and behaviors (Parker \& Endler, 1992). Our study measures the anxiety when facing a research methodology exam, specifically the assessment of the contents of a research designs course that includes information on statistics and statistical hypothesis testing.

Exams present four phases of anxiety that involve different coping responses: during the preparation or study of the topics the days preceding the exam to prevent the threat of the exam situation (anticipatory threat); confronting the stressor the day of the exam (threat of confrontation); the uncertainty when waiting for the results (threat of waiting for results); and facing the results (threat of the future) (Carver \& Scheier, 1994; Folkman \& Lazarus, 1985).

The phase of perception of anticipatory threat ('anticipatory anxiety') involves anxiety about the proximity or imminence of the assessment situation. It is a moment when the individual worries about the demands of the material and his/her possibilities, and thinks about how to prepare and regulate the adverse emotions and feelings linked to the future evaluation. Uncertainty about the results is high in this phase. The confrontation phase ('anxiety about confrontation') develops when the individual faces the stressor (the exam). It is the moment when the highest level of anxiety is experienced, especially its emotional component. The phase of waiting for the results ('anxiety about waiting') is the post-exam phase when the grades are still not known. During this phase, there is no longer anxiety about the content or nature of the exam, but there can be nervousness about the results. In 
the phase of facing the results ('anxiety about facing the results'), the grade earned is already known, and there is no uncertainty; now the worries are about the impact the grade can have on the individual's life.

Our study measured 'anticipatory statistics anxiety' (with 3 items) and 'statistics anxiety about confrontation' (1 item), conceptualized as state anxiety. In addition, the individual's level of 'trait anxiety' or general anxiety (1 item) is measured. It should be kept in mind that the three constructs mentioned were measured at different time points during the academic course: 1) in the first class at the beginning of the academic course when instructions are given that will guide the norms of the subject and 2) in evaluation situations (evaluation 1 and evaluation 2) and final exam of the subject. In this second area, the individuals must respond to trait, anticipatory, and confrontation anxiety before beginning the exam.

The two objectives of our research are:

1) To study the change throughout a quarter (training period that ends with a final exam) in the students' levels of trait anxiety and statistics state anxiety in the research designs subject in the methodology area of the Psychology degree, by means of a repeatedmeasures longitudinal study with four measurement points: first day of class (beginning of September), in the first evaluation period (middle of October), in the second evaluation period (middle of November), and on the final exam.

3) The relationships will be analyzed between the students' performance on the final exam in the statistics and designs subject and the variables of students' state and statistics trait anxiety the day they take this final exam.

\section{Method}

\subsection{Participants}

The sample of participants is composed of 30 Psychology students (8 men, 26.7\% and 22 women, $73.3 \%$ ) who receive training in research methodology, with a mean age of 20.31 years $(\mathrm{SD}=3.76)$.

\subsection{Instruments}

Sociodemographic variables of sex and age.

Brief scale of the level of statistics anxiety (ESBREVEANSI) of Frias-Navarro \& Monterde-i-Bort, 2017). The scale is composed of 6 items. On the one hand, the scale has 4 items that measure the level of anticipatory anxiety. The items refer to the perceived anxiety when studying for a methodology exam, when thinking about the day of the 
methodology exam, when thinking about the methodology exam a day before the exam, and the moment before beginning the exam or evaluation of the methodology contents. Responses are given on a Likert-type scale ranging from 'not anxious' (1) to 'very anxious' (10). The internal consistency values measured with Cronbach's alpha are excellent at the four measurement times by adding together the four items that measure anticipatory anxiety. On the first day of class: alpha $=.891,95 \% \mathrm{CI}=.809, .943$; at the first evaluation: alpha $=.968,95 \% \mathrm{CI}=.944, .983$; at the second evaluation: alpha $=.975,95 \% \mathrm{CI}=.956$, .987 ; on the final exam: alpha $=945,95 \% \mathrm{CI}=.905, .971$. On the other hand, another item that measures trait anxiety ("in general, my level of anxiety in my daily life is...") is added to the ESBREVEANSI scale; this item is presented first on the questionnaire as item 1, followed by the four anticipatory anxiety items mentioned above. Trait anxiety is also rated on a Likert-type response scale with the format described above.

Measurement of the performance on the statistics and research design contents. The variable used to measure the academic achievement on the statistics and research design contents was the grade obtained on the final exam in the subject. The exam is a written test with 35 questions resolved individually during a 90-minute period. The responses are given by hand using a paper and pencil procedure with no computer support. The exam contents include the analysis of different research designs (between-groups ANOVA, within-groups ANOVA, block designs, mixed designs, and ANCOVA), interpreting and writing up the results of statistical tests, and interpreting outcomes of SPSS-type statistical programs. The students have to recognize which statistical test is the most appropriate in each research scenario, consult statistical tables to find the critical value, calculate and/or interpret descriptive statistics, tables, graphs, and the value of the statistical test, and make statistical decisions according to the $p$ value of probability obtained and the a priori alpha level established. In addition, the students have to make assessments about the concepts of the null hypothesis, alternative hypothesis, statistical power, confidence level, effect size, confidence interval, type of study methodology, validity of the results, and control of bias, along with summarizing and reporting the results following APA style. The grade can range from 0 to 10 , and errors are penalized.

\subsection{Procedure}

The administration of the different measurement instruments took place during class time, and they were completed individually in a self-administered format. Participation was voluntary. A first evaluation was carried out on the first day of the 2017/18 academic year (beginning of September) before the presentation of the teaching guide for the research designs subject. Later, three measurements were performed (a month and a half after the beginning of the class, two and a half months later, and at the final exam). The final exam represents $70 \%$ of the student's final grade, and the grades on evaluations 1 and 2 make up 
$15 \%$ of the final grade. The total percentage of the student's grade is completed with the elaboration of a research report type article using APA style.

\section{Results}

\subsection{Longitudinal analysis of trait anxiety and statistics anxiety}

Item 1. Regarding the level of general trait anxiety presented by the students (Item 1), there are no statistically significant differences between the means of the four time points studied $F(3,27)=.615, p=.586, \eta_{p}^{2}=.061$, Huynh-Feldt epsilon $\left.=.87\right)$. Trait anxiety does not change significantly throughout the quarter, and its mean value is around 4.9 on a scale from 1 to 10 . See table 1 (with means and standard deviations) and Figure 1 (only with the average scores).

Item 2. Regarding the students' level of anxiety when studying for the methodology exam, it can be observed that overall there are statistically significant differences between the means of the four time points studied $\left(F(3,27)=3.84, p=.013, \eta_{p}^{2}=.117\right.$, Huynh-Feldt epsilon $=.97)$. See table 1 and Figure 1 . However, the analysis of the pairwise comparisons of means using the Bonferroni test did not detect statistically significant differences. The results show that, in descriptive terms, on the first day of class the students manifest a higher level of anxiety (mean $=6.53$ ), and the tendency of the means is to gradually decline as instruction is received on the design and hypothesis testing contents. The students' uncertainty before studying the material may be able to explain the higher level of anxiety on the first day of class.

Item 3. Regarding the students' level of anxiety when they think about the methodology exam the day before it, there are statistically significant differences among the means of the four time points studied $\left(F(3,27)=3.56, p=.024, \eta_{p}^{2}=.109\right.$, Huynh-Feldt epsilon = .85). See table 1 and Figure 1. The results show that, in descriptive terms, on the first day of class the students express a higher level of anxiety (mean $=6.93)$, and the tendency of the means is to decline as students receive instruction in the research design and hypothesis testing contents. Again, it is likely that students' uncertainty before studying the material would explain the higher level of anxiety on the first day of class. 
Table 1. Results of the longitudinal analysis of trait anxiety and statistics anxiety.

\begin{tabular}{lcccccccccc}
\hline Items & $\begin{array}{l}\text { First day of } \\
\text { class }\end{array}$ & \multicolumn{2}{c}{$\begin{array}{c}\text { First } \\
\text { evaluation }\end{array}$} & $\begin{array}{c}\text { Second } \\
\text { evaluation }\end{array}$ & Final exam & $p$ & $\eta^{2}$ \\
\hline & Mean & SD & Mean & SD & Mean & SD & Mean & SD & Mean & SD \\
\hline $\begin{array}{l}\text { 1. Trait } \\
\text { anxiety }\end{array}$ & 4.97 & 1.99 & 4.93 & 2.12 & 4.93 & 1.98 & 4.63 & 2.03 & .586 & .061 \\
$\begin{array}{l}\text { 2. Study for } \\
\text { the exam }\end{array}$ & 6.53 & 2.16 & 6.07 & 2.26 & 5.87 & 2.22 & 5.60 & 2.01 & .013 & .117 \\
$\begin{array}{l}\text { 3. The day of } \\
\text { the exam }\end{array}$ & 6.93 & 2.24 & 6.30 & 2.42 & 6.340 & 2.38 & 6.00 & 2.33 & .024 & .109 \\
$\begin{array}{l}\text { 4. Before the } \\
\text { exam }\end{array}$ & 7.4 & 2.19 & 6.67 & 2.43 & 6.83 & 2.46 & 6.53 & 2.46 & .124 & .189 \\
$\begin{array}{l}\text { 5. At that } \\
\text { moment }\end{array}$ & 4.2 & 1.95 & 6.33 & 2.54 & 6.73 & 2.48 & 6.93 & 2.50 & $<.001$ & .400 \\
\hline
\end{tabular}

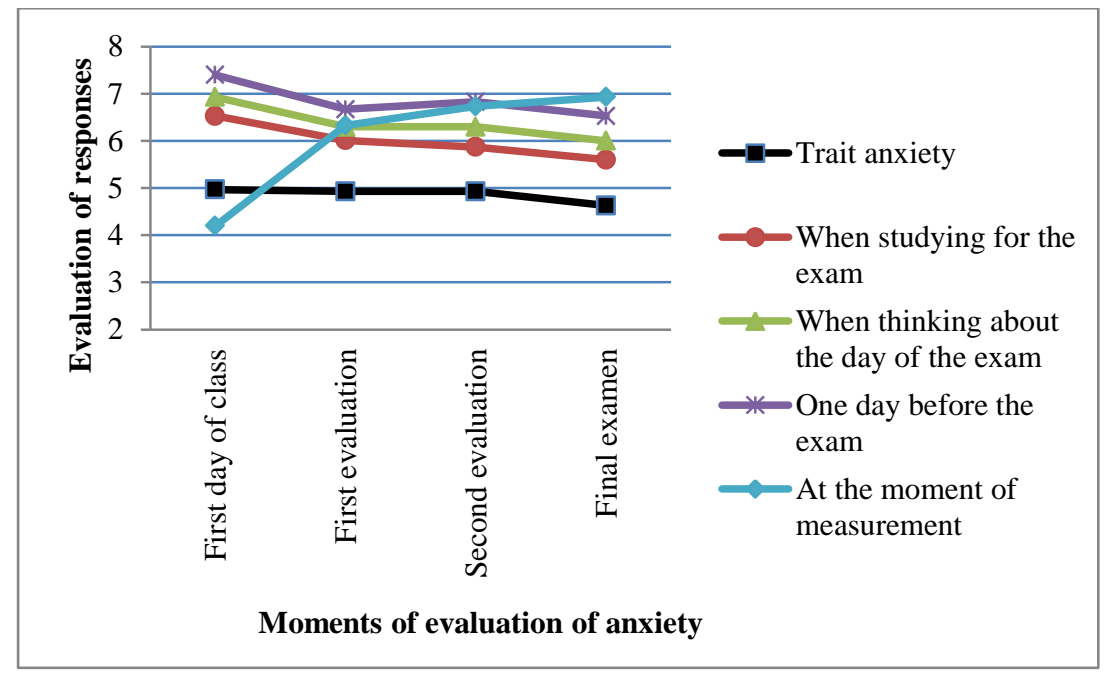

Figure 1. Graphic representation of the results of the longitudinal analysis (the response is measured from 1 to 10).

Item 4. Regarding the students' level of anxiety when they think about the methodology exam the day before it is held, statistically significant differences can be observed among the means of the four time points studied $\left(F(3,27)=3.240, p=.030, \eta_{p}^{2}=.101\right.$, HuynhFeldt epsilon =.92). See table 1 and Figure 1 . However, again the pairwise analysis of differences in means using the Bonferroni procedure does not detect statistically significant 
differences. However, in descriptive terms, the first day of class is when the students have the highest level of statistics anxiety (mean $=7.4$ ), which declines to 6.53 on the day of the final exam.

Item 5. In the case of reporting the students' levels of anxiety at the precise moment when they are measured (Item 5) (that is, during the class on the first day of the course, or before beginning the two evaluations and at the final exam), the results show that, in descriptive terms, state anxiety increases as the moment of the final exam on the statistical contents draws near. The results of the repeated-measures ANOVA indicate that there are statistically significant differences among the mean anxiety scores at the four evaluation moments $\left(F(3,27)=19.37, p<.001, \eta_{p}^{2}=.400\right.$, Huynh-Feldt epsilon $\left.=.71\right)$. See table 1 and Figure 1. The pairwise analysis of differences in means using the Bonferroni test indicates that the level of anxiety reported at the moment of attending the first methodology class is statistically inferior to the level of anxiety reported at the moments of the first evaluation test $(p=.001)$, the second evaluation test $(p<.001)$, and the final exam in the subject $(p<.001)$. Regarding the other comparisons, no statistically significant differences are detected. Therefore, there is a tendency to increase state anxiety related to statistics throughout the academic course, but there is only a statistically significant difference between the first day of class of the course, when its level is lower ( to later evaluation moments, when mean values of around 6.7 are reached.

\subsection{Final achievement and trait anxiety and state statistics anxiety}

The results indicate that the grade on the final exam is significantly related to the students' anxiety when they study for the exam (Item 2) $(-.401, p=.028)$ and when they think about the exam one day before it, (Item 4$)(-.401, p=.040)$. The relationships are not statistically significant for trait anxiety (Item 1$)(-.101, p=.594)$ when they think about the day of the exam (Item 3) $(-.327, p=0.078)$ and when they express the state anxiety they have at the exact moment before beginning the test (Item 5) $(-.104, p=.584)$.

\section{Discussion}

The results of our study provide four especially relevant conclusions: 1) the level of statistics anxiety of the students during the first day of class in the statistics and design class, where the contents, evaluation, and program are presented, reaches its highest levels; 2) state-type statistics anxiety gradually declines as the course progresses and knowledge is gained about the contents of the subject; 3) students' trait anxiety remains constant throughout the course; and 4) the students' achievement maintains an inverse relationship with statistics anxiety when they are studying the material and when they think about the 
exam the day before it is held. The students with the best performance on the exam have less statistics anxiety.

In our study, during the academic year, there is no type of psychological intervention carried out to reduce students' statistics anxiety. This reduction in anxiety is probably due to the personal mastery of the course contents that gradually takes place. Thus, it would be interesting to find out whether the profile obtained occurs in subject matters or topics that are not from the methodology area, in order to verify whether the effect is maintained and the findings can be generalized. If the students show a high level of anxiety on the first day of class (regardless of the subject matter), then the results of our study would help to give professors guidelines to try to mitigate this first-day anxiety. One of the practical implications of our results for higher education teaching is that the presentation of the subject matter on the first day of class is a key moment to reduce students' anxiety about the training they are going to receive throughout the course.

The main limitations of our study are linked to the sample of participants because probabilistic sampling was not used, and to the sample size. Therefore, our results are exploratory and oriented toward a future study with a larger sample size. It would also have been interesting to analyze the progression of the grades and anxiety over time. We will try to overcome these limitations in our next study, which will be planned based on the data obtained and extended to course contents from different research methodology areas. In addition, it would be interesting to verify whether, in another type of training such as medicine or veterinary sciences where students also receive statistics instruction, an anxiety profile similar to the one obtained in this study is found. The results of our study open up various paths for future research that could provide recommendations for professors related to students' anxiety about studying the contents of different courses, in an effort to improve their students' final performance. Financial support: Project UV-INV-AE17-698616. University of Valencia. Spain.

\section{References}

Badenes-Ribera, L., Frias-Navarro, D., Monterde-i-Bort, H., \& Pascual-Soler, M. (2015). Interpretation of the $\mathrm{p}$ value: A national survey study in academic psychologists from sapin. Psicothema, 27, 290-295.

Carver, C. S., \& Scheider, M. F. (1994). Situational coping and coping dispositions in a stressful transaction. Journal of Personality and Social Psychology, 66, 184-195.

Chernoff, E. J., \& Sriraman, B. (Eds) (2014). Probabilistic thinking: Presenting plural perspective-advances in mathematics education. Dordrecht, Netherlands: Springer Science + Business Media. 
Folkman, S., \&Lazarus, R. S. (1985). If it changes it must be a process: study of emotion and coping during three stages of a college examination. Journal of Personality and Social Psychology, 48, 150-170.

Frías-Navarro, D. \& Monterde-i-Bort, H. (2017). Escala breve del nivel de ansiedad estadística-5 (ESBREVEANSI). University of Valencia. Spain. Available: https://www.uv.es/friasnav/unidinves.html

Monterde-i-Bort, H. Frías-Navarro, D.; Pascual Llobell, J. (2010). Uses and abuses of statistical significance test and other statistical resources: A comparative study. European Journal of Psychology of Education, 25, 429-447.

Onwuegbuzie, A. J. (2004). Academic procrastination and statistics anxiety. Assessment \& Evaluation in Higher Education, 29, 3-19.

Onwuegbuzie, A. J., \& Wilson, V. A. (2003). Statistics Anxiety: nature, etiology, antecedents, effects, and treatments-a comprehensive review of the literature. Teaching in Higher Education, 8, 195-209.

Parker, J. D. A. \& Endler, N. S. (1992). Coping with coping assessment: A critical review. European Journal of Personality, 6, 321-344. 